\title{
Physio-anatomical responses of tobacco under caffeine stress
}

\author{
R. ALKHATIB ${ }^{*+}$, B. ALKHATIB ${ }^{* *}$, L. AL-EITAN ${ }^{* *}$, N. ABDO $^{* * *}$, M. TADROS ${ }^{* * * *}$, and E. BSOUL ${ }^{* * * * *}$ \\ Department of Biotechnology and Genetic Engineering, Faculty of Science and Arts, Jordan University of Science \\ and Technology, Irbid 22110, Jordan* \\ Department of Applied Biological Sciences, Faculty of Science and Arts, Jordan University of Science and Technology, \\ Irbid 22110, Jordan ${ }^{* *}$ \\ Department of Public Health, Faculty of Medicine, Jordan University of Science and Technology, Irbid 22110, Jordan ${ }^{* * *}$ \\ Department of Natural Resources and Environment, College of Agriculture, Jordan University of Science and Technology, \\ Irbid 22110, Jordan ${ }^{* * * *}$ \\ Department of Biology and Biotechnology, The Hashemite University, Zarqa, Jordan ${ }^{* * * * *}$
}

\begin{abstract}
Caffeine, a purine alkaloid, is reported to act both as an inducer or inhibitor to plant growth in various species. The aim of this study was to examine the effect of exogenous caffeine on tobacco (Nicotiana tabacum) plants, a plant that does not naturally synthesise caffeine. A hydroponic experiment was carried out in a growth chamber for $14 \mathrm{~d}$ using Hoagland's solution supplemented with 0 (control), 25, 50,100,1,000; and 5,000 $\mu \mathrm{M}$ caffeine. None of the investigated caffeine concentrations significantly decreased the net photosynthetic rate except the highest concentrations of 1,000 and $5,000 \mu \mathrm{M}$. Light microscopy of thick-sectioned roots showed that $1,000 \mu \mathrm{M}$ and $5,000 \mu \mathrm{M}$ caffeine-treated plants possessed deformed epidermal cells, reduced number of cortical cells, and deformed vascular tissues with cells exhibiting thickened xylem walls as compared with control plants. Moreover, transmission electron micrographs of roots revealed that mitochondria and the plasma membrane were affected.
\end{abstract}

Additional key words: chloroplast; photosynthetic rate; stomatal conductance; transmission microscope; transpiration rate; xylem.

\section{Introduction}

Under various environmental stresses, plants adapt and enhance acclimation responses through retrograde signalling pathways (Sun and Guo 2016). The study of stress impact on plants is one of the fast-growing areas of plant research worldwide. In general, environmental stresses affect the integrity of cell structure and function and thus can be determined by examining individual cells (Čiamporová and Mistrík 1993). For example, under severe environmental stresses, such as drought, salt, cold, heat, and chemical pollutants, most plant structural components are either damaged or deformed causing loss of function or altered physiology of these components. Such stresses, generally, act cooperatively and elicit adaptive as well as protective mechanisms (Vinocur and Altman 2005). In one type of response, plants synthesise secondary metabolites, such as alkaloids and various phenols including flavonoids, steroids, and terpenoids, to cope with these stresses (Gilbert et al. 1997, Hadacek and Kraus 2002, Dhanapackiam and Iiyas 2010). These secondary metabolites presumably function in adaptation of plants to external environments.

Caffeine (1,3,7-trimethylxanthine) is an alkaloid found naturally in young leaves and immature fruits of more than 100 species including tea (Camellia sinensis), coffee (Coffea), cacao (Theobroma cacao), and kola (Cola nitida) (Ashihara and Crozier 1999, 2001; Ashihara et al. 2008). Caffeine biosynthesis is known to be linked to both abiotic and biotic stress. However, the physiology of caffeine in plants is poorly understood. Several plant studies suggested that exogenous and/or endogenous caffeine may act as a growth enhancer, while others demonstrated its function as a plant growth inhibitor (Montes et al. 2014).

Received 24 May 2017, accepted 5 September 2017, published as online-first 12 April 2018.

${ }^{+}$Corresponding author; fax : + 962 (0) 2 7095123, e-mail: rqalkhatib@just.edu.jo

Abbreviations: $E$ - transpiration rate; $g_{\mathrm{s}}-$ stomatal conductance; $P_{\mathrm{N}}-$ net photosynthetic rate; TEM - transmission electron microscope; SEM - standard errors for the means.

Acknowledgements: This work was supported by the Deanship of Scientific Research at Jordan University of Science and Technology, for their generous grant No. 2013/262. The authors thank Dr. Marshall Sundberg for his thoughtful comments editing the manuscript Also, the authors would like to thank Mr. Munier Alkhdour and Mu'tz Al-Zoubi for use of the TEM facilities and for technical assistance. 
Mohanpuria and Yadav (2009) showed that Arabidopsis and tobacco seeds that were grown for $17 \mathrm{~d}$ in MS media containing 1 and $5 \mathrm{mM}$ caffeine suffered from obvious decrease in shoot and root length, leaf discoloration (yellowing), and diminished root branching. CurlangoRivera et al. (2010) reported that caffeine concentrations between 10,000 and $25,000 \mu \mathrm{M}$ reduced the number of root cells in Pisum sativum seedlings. Moreover, Anaya et al. (2002) reported that root mitosis was inhibited in Zea mays treated with $2500 \mu \mathrm{M}$ caffeine. In contrast, the mean height in plants of Capsicum annum treated with 2,57538,660 $\mu \mathrm{M}$ caffeine increased (Kumar and Tripathi 2004).

Thus, caffeine has a potential as an environmentally acceptable herbicide as well as its proven value as an effective pesticide (Mathavan et al. 1985, Hollingsworth

\section{Materials and methods}

Plants and growth conditions: Tobacco seeds (Nicotiana tabacum L. var. Turkish) were germinated and grown in potting soil (Thimar Manufacturing Chemical and Agricultural Manure, Jordan) for 4 weeks. Two week-old seedlings with the same number of leaves and heights $(5 \mathrm{~cm})$ were carefully removed from the soil and their roots were thoroughly washed with water, then transferred to a hydroponic system, with Hoagland's nutrient solution (Caisson Laboratories Inc., UT, USA), and transferred to a growth chamber (model VS-3DM, Bionex, Korea) at a PPFD of 250 to $300 \mu \mathrm{mol}$ (quantum) $\mathrm{m}^{-2} \mathrm{~s}^{-1}$. The temperature was $30^{\circ} \mathrm{C}$ (day) and $23^{\circ} \mathrm{C}$ (night), and the relative humidity $(\mathrm{RH})$ was approximately $60 \%$. The seedlings were grown in the light and in the dark under circadian illumination of 16-h light/8-h dark (Alkhatib et al. 2016). A pilot study was conducted with different concentrations of caffeine (AZ Chem for chemicals, cat\#1590250) (25, 50, 100, 200, 500, 1,000; 5,000; and 20,000 $\mu \mathrm{M})$. Based on morphological observations and time of exposure, the following concentrations were selected for the experiment: 0 (control), 25, 50, 100; 1,000; and 5,000 $\mu \mathrm{M}$ mixed with Hoagland's nutrient solution. Treatment solutions were replaced every three days. The experimental design was a randomized complete block, with three treatments and three replicates per treatment.

Physiological parameters: Two fully-expanded mature leaves (the third and fourth from the top of each plant) were selected to measure net photosynthetic rate $\left(P_{\mathrm{N}}\right)$, stomatal conductance $\left(g_{\mathrm{s}}\right)$, and transpiration rate $(E)$. Leaves were measured at $6.25 \mathrm{~cm}^{2}$ leaf area using an infrared gas analyzer (CI-340, CID Bio-Science Inc., Camas, WA, USA). All measurements were taken at PPFD of $1,300 \mu \mathrm{mol}$ (quanta) $\mathrm{m}^{-2} \mathrm{~s}^{-1}$. Plants treated with $5,000 \mu \mathrm{M}$ caffeine were measured after $5 \mathrm{~d}$ of post exposure to caffeine (data not shown), since most of their leaves were completely necrotic after $14 \mathrm{~d}$ from the treatment. et al. 2002, Kim et al. 2006). However, the physiological and anatomical effects of caffeine on plant roots and leaves have not been investigated until recently. Our 2016 study reported that caffeine stress caused changes in morphological, biochemical, and ultrastructural characteristics of Nicotiana tabacum leaves (Alkhatib et al. 2016). In this current study, we hypothesise that plants grown in high concentrations of caffeine exhibit physiological, structural, and ultrastructural alterations both in leaf and root cells. We concluded that the dramatic drop of the photosynthetic rate in the leaves of plants and the high concentrations of caffeine were correlated. Tobacco was chosen as a model study system because it does not naturally produce caffeine.

Light and transmission electron microscopy: Mature root and leaf samples (the third and fourth from the top of each plant) $(0.5-1.0 \mathrm{~cm})$ from caffeine-treated and control plants were prepared for light and transmission microscopy following the same protocol as described by Alkhatib et al. (2016). Briefly, samples were fixed in $2.5 \%$ glutaraldehyde buffered at $\mathrm{pH} 7.4$ in $0.1 \mathrm{M}$ cacodylate buffer overnight at $4^{\circ} \mathrm{C}$. Samples were washed with $0.1 \mathrm{M}$ cacodylate five times for $2 \mathrm{~min}$ each. Then, samples were post-fixed in $1 \%$ osmium tetroxide, dehydrated in a graded series of ethanol $(50,70,80,95$, and $100 \%)$, and embedded in freshly prepared Spurr's resin (Spurr 1969). For light microscopy, thin sections of resin-embedded leaf and root tissues $(1.0 \mu \mathrm{m})$ were cut using a Leica ultramicrotome and stained with 1\% toluidine blue aqueous (Epoxy Tissue Stain, EMS, PA, USA), and examined using an Olympus light microscope (Olympus CH20 BIMF200, Olympus Optical Co. Ltd., Japan) equipped with a digital camera (Amscope, MU100, China). For transmission electron microscopy, ultrathin sections $(70 \mathrm{~nm})$ of root and leaf samples were cut with a diamond knife (Diatome Ltd., Bienne, Switzerland) using a Leica ultramicrotome (Leica, Switzerland), stained with uranyl acetate (Epstein and Holt 1963 ) then by lead citrate (Reynolds 1963), and examined with a transmission electron microscope (TEM) running at $60 \mathrm{KV}$ (Zeiss EM 10 OCR, Germany).

Statistical analysis: All statistical analyses for physiological parameters $\left(P_{\mathrm{N}}, g_{\mathrm{s}}\right.$, and $\left.E\right)$ were conducted using PC SAS (v. 9.2; SAS Institute, Cary, NC, USA). Analysis of variance (ANOVA) and Dunnett's tests were used for the analysis of physiological parameters; one-way ANOVA was used to assess significance differences between different concentrations for each physiological parameter at $\alpha=0.05$. Dunnett's test was used to assess significant differences between treatments. Graphs of physiological parameters were made using Graph pad Prism 5. 


\section{Results}

The $P_{\mathrm{N}}$ for control plants was $6.08 \mu \mathrm{mol}\left(\mathrm{CO}_{2}\right) \mathrm{m}^{-2} \mathrm{~s}^{-1}$. In contrast, $P_{\mathrm{N}}$ significantly decreased in $1,000 \mu \mathrm{M}$ caffeinetreated plants to $-0.58 \mu \mathrm{mol}\left(\mathrm{CO}_{2}\right) \mathrm{m}^{-2} \mathrm{~s}^{-1}$. No significant changes in $P_{\mathrm{N}}$ were found for leaves exposed to other caffeine concentrations as compared with control plants (Fig. $1 A$ ). $P_{\mathrm{N}}, g_{\mathrm{s}}$, and $E$ for plants treated with $5,000 \mu \mathrm{M}$ dramatically decreased at day 5 (data not shown). However, both $g_{\mathrm{s}}$ and $E$ exhibited significant decreases in leaves grown in $50,100,1,000 \mu \mathrm{M}$ caffeine at day 14 as compared with control plants (Fig. $1 B, C$, respectively).

Light microscopy of roots for control plants exhibited well-organized epidermal cells with multi-layer cortical cells. In addition, the vascular tissue showed well-arranged xylem and phloem cells. In contrast, 1,000 and 5,000 $\mu \mathrm{M}$ caffeine-treated plants showed deformed epidermal cells, expanded intercellular space in the cortex, thickened cell walls in the vascular tissues (mainly xylem), impaired shape of the cells, and reduced number of cortical cell layers (Fig. 2E,F) as compared with the control root thick sections (Fig. 2A). Moreover, plants treated with 25, 50, and $100 \mu \mathrm{M}$ caffeine (Fig. $2 B, C, D$, respectively) showed normal epidermal cells as well as regular-shape cortical cells with normal intercellular spaces. Thus, the vascular tissue (xylem and phloem) arrangement was similar to those in control plants exhibiting no thickened xylem (x) cell walls.

Control plants showed mitochondria with welldeveloped system of cristae (Fig. $3 A$ ), while the TEM images of the root system grown under 50 and $100 \mu \mathrm{M}$ caffeine exhibited mitochondria with dilated cristae near the plasma membrane (Fig. 3B,C). Plants treated with $1,000 \mu \mathrm{M}$ caffeine exhibited elongated mitochondria with deformed cristae system (Fig. 3D), while 5,000 $\mu \mathrm{M}$ caffeine-treated plants showed no visible mitochondria near the plasma membrane (Fig. 3E). Interestingly, the plasma membrane in the root cells of $50 \mu \mathrm{M}$ and $100 \mu \mathrm{M}$ caffeine-treated plants exhibited invaginations (Fig. 3C,F) not observed in control plants (Fig. 3A). Moreover, the 100 $\mu \mathrm{M}$ caffeine-treated plants also showed increased vacuolation in the cortical region (Fig. $3 H$ ).

The light microscopic images of control, $50 \mu \mathrm{M}$, and $100 \mu \mathrm{M}$ caffeine-treated plant leaves showed regular epidermal cell layers, a well-organized palisade layer, and a well as spongy layer (Fig. 4A,C,E). However, the electron micrograph image of $100 \mu \mathrm{M}$ caffeine-treated plant showed more plastoglobules than in control plant (Fig. $4 F$ ). The 1,000 and 5,000 $\mu \mathrm{M}$ caffeine-treated plants

\section{Discussion}

Among the photosynthetic parameters examined in this study, $g_{\mathrm{s}}, E$, and $P_{\mathrm{N}}$ were significantly reduced by caffeine stress $(50,100 ; 1,000$; and 5,000 $\mu \mathrm{M})$, however, a signifi-

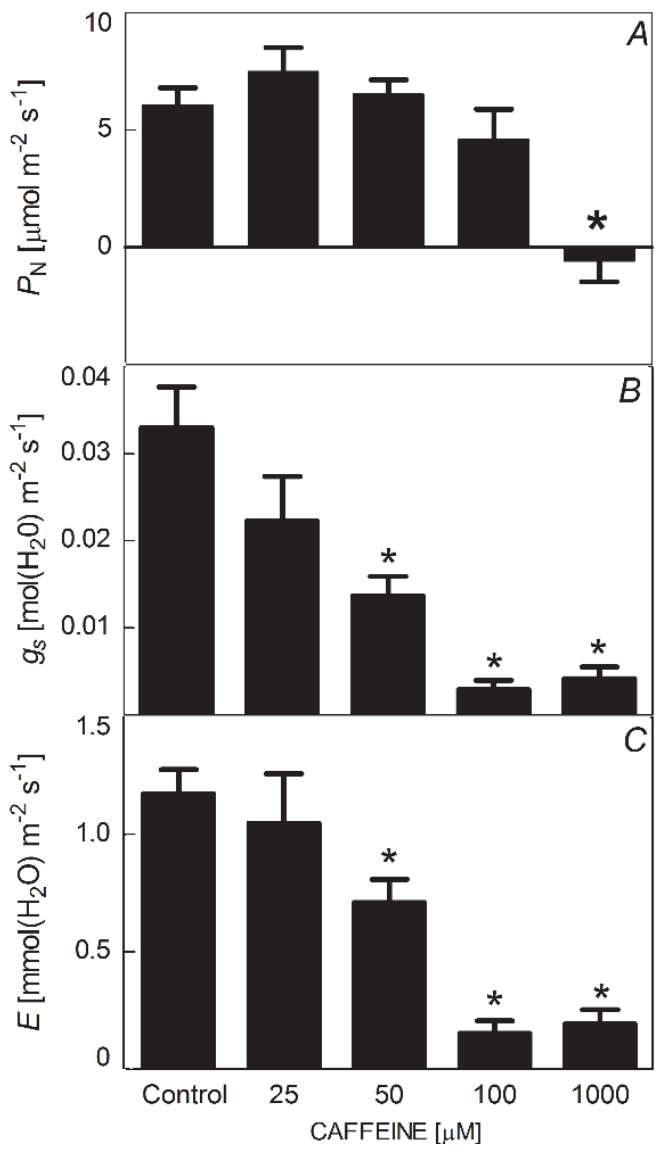

Fig. 1. Changes in photosynthetic parameters in Nicotiana tabacum $(A)$ net photosynthetic rate $\left(P_{\mathrm{N}}\right),(B)$ stomatal conductance $\left(g_{\mathrm{s}}\right),(C)$ transpiration rate $(E)$. Data represent the means $( \pm \mathrm{SE})$ of three independent experiments. ${ }^{*}$ - values significantly different from the control (Dunnett's test with $P<0.05$ ).

showed deformed epidermal cells and palisade layers (Fig. 4G,I). Moreover, plants exposed to 5,000 $\mu \mathrm{M}$ exhibited disturbed and very compact spongy layer and the upper epidermis showed the presence of a trichome (Fig. 4I). Similarly, TEM images of the control and $50 \mu \mathrm{M}$ caffeine-treated plant leaves revealed no differences in their chloroplasts (Fig. $4 B, D$, respectively). The grana of chloroplasts in plants treated with $100 \mu \mathrm{M}$ caffeine were reduced as compared with control plants, meanwhile plants treated with 1,000 and $5,000 \mu \mathrm{M}$ caffeine were extremely reduced, and the chloroplasts were enlarged with noticeably bulged outer membrane (Fig. $4 H, J$ ).

cant drop in $P_{\mathrm{N}}$ was observed only at 1,000 and $5,000 \mu \mathrm{M}$ caffeine concentrations. This suggests that $g_{s}$ and $E$ might not be the main limiting factors in seedling retardation 

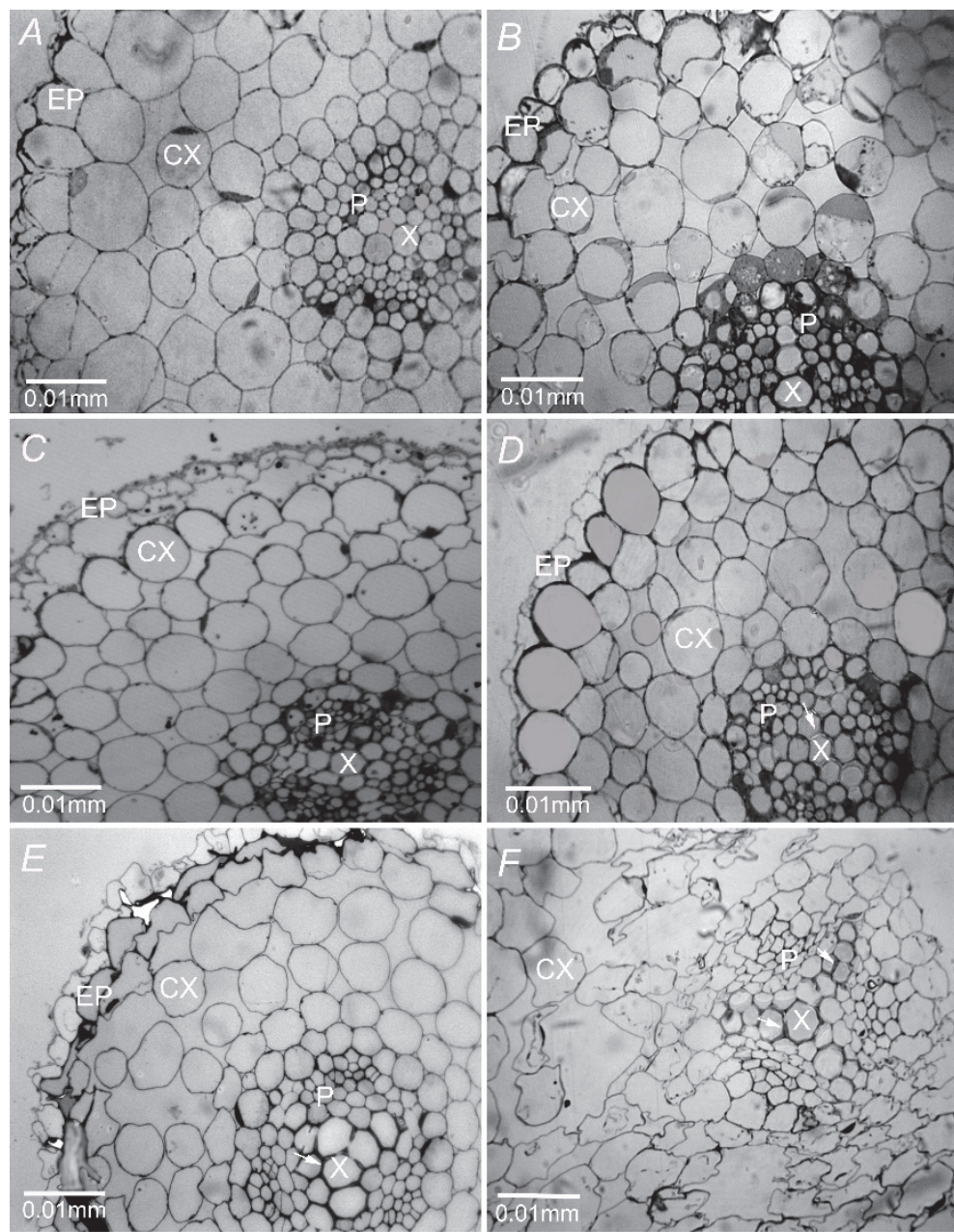

Fig. 2. Light microscopic images showing thick sections of Nicotiana tabacum root. (A) control root. The 25, 50, and $100 \mu \mathrm{M}$ caffeine-treated plants $(B, C$, $D$, respectively). (E) $1,000 \mu \mathrm{M}$ caffeine-treated plant showing minor deformation of the cortical cells $(\mathrm{CX})$ and thickened xylem (X) (arrow). (F) 5,000 $\mu \mathrm{M}$ caffeine-treated plant showing major disruption in the organization of the cortical cells $(\mathrm{CX})$ and vascular bundles [xylem (X) and phloem (P)]. Arrow indicates thickened xylem $(\mathrm{X})$. Cell wall $(\mathrm{CW})$, epidermal cells (EP), cortical cells $(\mathrm{CX})$, phloem (P), and xylem (X). Bar equals $0.01 \mathrm{~mm}$. and the influence of caffeine on the photosynthetic apparatus is indirect. This could be due to shifting of Rubisco activity towards oxygenation reactions instead of carboxylation (Pietrini et al. 2003). In addition, Krapp and Stitt (1995) showed that decreased activity of Rubisco is often correlated with sugar accumulation in leaves. Previously, we demonstrated that a drastic reduction of $P_{\mathrm{N}}$ is accompanied by an increase of sugar content in the leaves of 1,000 and 5,000 $\mu \mathrm{M}$ caffeine-treated plants (Alkhatib et al. 2016). Mohanpuria and Yadav (2009) documented that the expression of Rubisco in tobacco plants was downregulated upon caffeine exposure and could be the keystone factor in seedling retardation under those conditions.

In situ microscopic detection of small molecules such as caffeine in leaf and root materials is extremely difficult (Ferreira et al. 1998). Furthermore, it is likely that any caffeine present is extracted during fixation, although it likely has osmotic effects on plant tissues (Coetzee and van der Merwe 1987). Nevertheless, its impact on the structure and ultrastructure was seen very clearly in both root and leaf cells. Previous studies of the effect of caffeine on a diversity of crops reported contradictory effects on plant growth, acting both as an enhancer or inhibitor of growth.
This could be due to application of different caffeine concentrations, different periods of application, or examining effects on different plant organs (Montes et al. 2014). Khanam et al. (2000) reported that in Duboisia myoporoides tropane alkaloids were localized in the xylem cells of roots. In the present study, the xylem wall thickeneding in the roots of plants treated with 1,000 and $5,000 \mu \mathrm{M}$ caffeine could indicate the possible accumulation of caffeine in the vascular tissue, causing the vascular bundle to lose its integrity (Fig. $2 E, F$ ).

Cross-sectioned leaves of plants treated with $5,000 \mu \mathrm{M}$ caffeine showed severe deformation of palisade parenchyma cells as well as compaction of spongy parenchyma cells. Moreover, the vascular tissue was deformed and compact (Fig. 4I). Mondolot et al. (2006) suggested that in Camellia canephora leaves alkaloids, i.e. caffeine, was localized in the phloem cells. In plants treated with 50 and $100 \mu \mathrm{M}$ caffeine (Fig. 4D,F), the ultrastructural organization of the leaf chloroplasts was similar to those in control plants (Fig. 4B). In contrast, deformed chloroplasts of different shapes were observed in plants treated with 1,000 and 5,000 $\mu \mathrm{M}$ caffeine (Fig. 4H,J) (Alkhatib et al. 2016).

Mitochondrial responses, including reduction in 

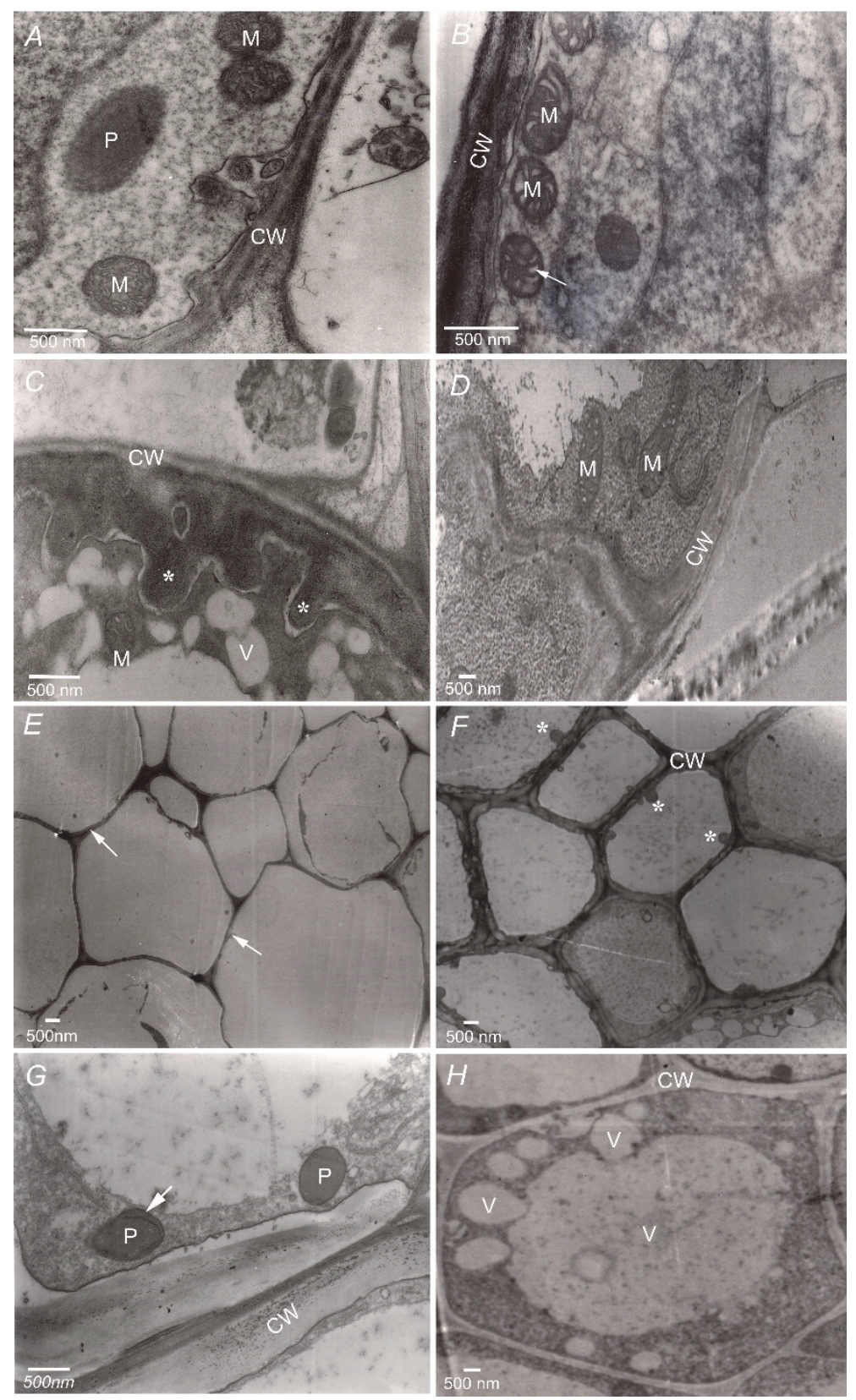

Fig. 3. Transmission electron micrographs of Nicotiana tabacum root cortical cells of control and caffeinetreated plants. $(A)$ control plant, $(B) 50 \mu \mathrm{M}$ caffeinetreated plant showing dilated cristae (arrow), $(C)$ $100 \mu \mathrm{M}$ caffeine-treated plant showing invaginations of plasma membrane (asterisks), (D) 1,000 $\mu \mathrm{M}$ caffeine-treated plant showing elongated mitochondria, $(E) 5,000 \mu \mathrm{M}$ caffeine-treated plant showing cortical cell walls (arrow) and no visible mitochondria were observed; $(F)$ thickened cell walls $(\mathrm{CW})$ of $50 \mu \mathrm{M}$ caffeine-treated plant exhibiting plasma membrane invaginations (asterisks), (G) $50 \quad \mu \mathrm{M}$ caffeine-treated plant with few lamella (arrow), $(H)$ $100 \mu \mathrm{M}$ caffeine-treated plant exhibiting vacuolation. Mitochondria (M), cell wall (CW), small vacuoles (V), plastid (P). Bar equals $500 \mathrm{~nm}$.

number of cristae, have also been reported for various types of environmental stresses. Čiamporová (1987) suggested these alternations may be directly related to changes in respiration activity of the mitochondria. For example, ATP synthesis decreased by $40 \%$ as early as $3 \mathrm{~h}$ after the onset of water stress. In addition, Vartapetian et al. (2003) reported that destructive, degradative and adaptation rearrangments occured in mitochodria membranes in plants after transfering them from aerobic to anaerobic environment.

Finally, in stressed root cells, an increase in the number of small vacuoles was reported. For example, low temperature-induced transformation of large vacuoles into numerous small ones was found (Čiamporová and Mistrík 1993). Vacuolation in the root cells is very crucial for both the accumulation of osmotically active substances and osmotic adjustment under salt or water stresses, respectively (Hajibagheri et al. 1985, 1987). Plants treated with $100 \mu \mathrm{M}$ caffeine showed very visible invaginations of the plasma membrane (Fig. 3C). The same pattern was observed in maize, broad bean, and barley root cells dehydrated by withholding water (Čiamporová and Mistrík 1993). Endocytosis of polysaccharide product and its digestion was confirmed in these cells and evaluated as an important reaction to water deficit (Nishizawa et al. 1989). The same pattern was also seen in the epidermal cells of 100 and $500 \mu \mathrm{M} \mathrm{Pb}$-treated Nicotiana tabacum roots; this inward invagination suggests a mechanism of $\mathrm{Pb}$ detoxification in order to protect the cell contents from its effects, by forming pinocytotic vacuoles (Alkhatib et al. 2013). 

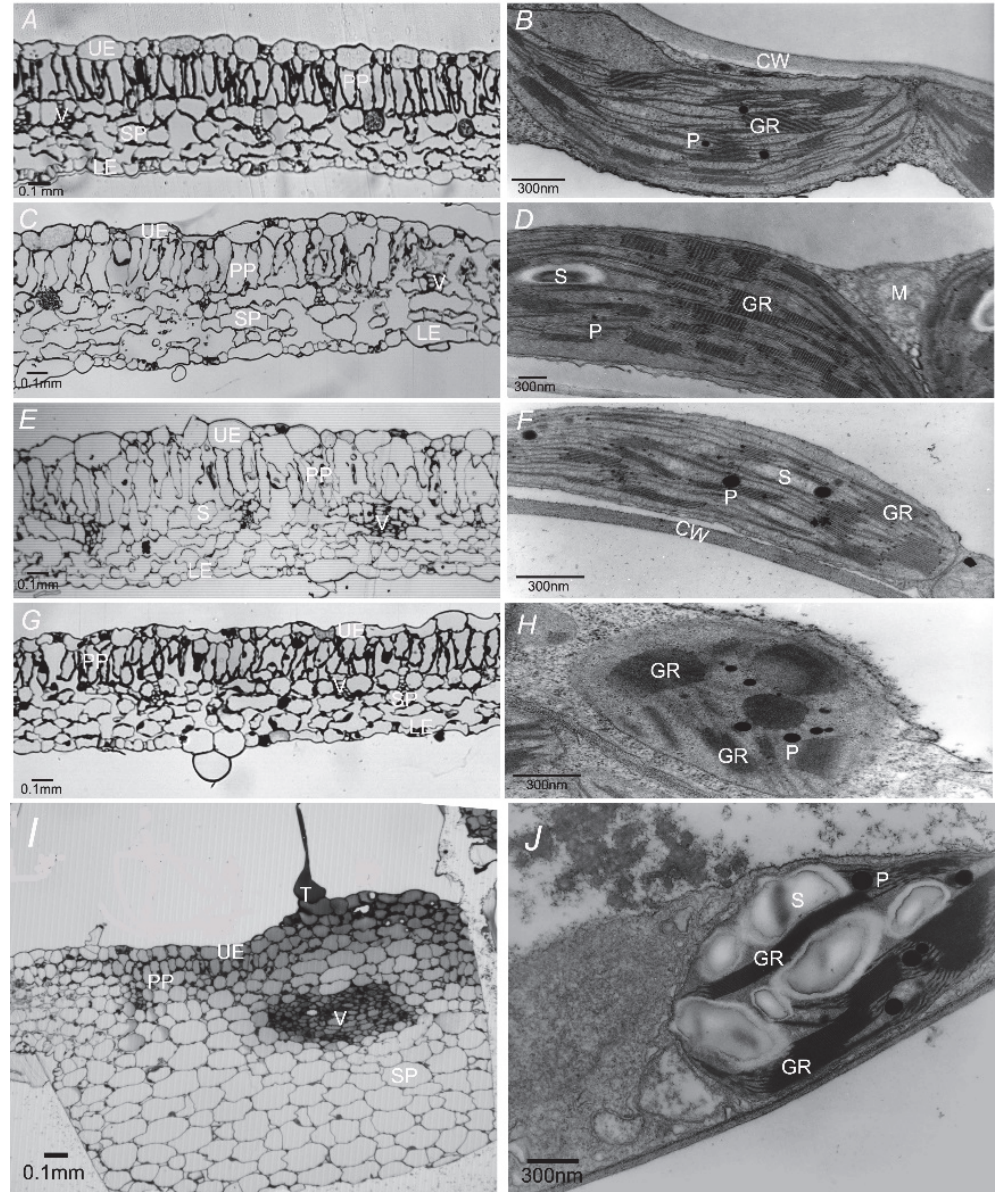

Fig. 4. Thick and thin leaf sections of Nicotiana tabacum control and caffeine-treated plants. $(A)$ micrograph images of control plant $(A, B)$. Caffeinetreated plants with $50 \mu \mathrm{M}(C, D)$ and $100 \mu \mathrm{M}(E)$ did not show any visible deformation. (F) $100 \mu \mathrm{M}$ caffeine-treated plant with few plastoglobules. Micrograph images of $1,000 \mu \mathrm{M}$ caffeine-treated plant $(G, H)$ exhibited deformed thylakoids membrane. (I) thick section of $5,000 \mu \mathrm{M}$ caffeine-treated plant showing deformed leaf structure, $(J)$ electron micrograph of $5,000 \mu \mathrm{M}$ caffeine-treated plant chloroplast exhibited deformed thylakoids membrane associated with large starch grains and plastoglobules. Upper epidermis (UE), palisade parenchyma layer (PP), spongy parenchyma layer (SP), vascular tissue (V), lower epidermis (LE), grana (GR), plastoglobules (P), starch (S). Bar equals $0.1 \mathrm{~mm}(A, C, E, G), 300 \mathrm{~nm}(B, D, F, H, J)$.
Conclusion: This is the first study that demonstrates caffeine-induced alterations in photosynthetic parameters $\left(P_{\mathrm{N}}, g_{\mathrm{s}}\right.$, and $\left.E\right)$, structural, and ultrastructural components of root and leaf cells. It suggests that more studies on caffeine's effect on different species are needed to elaborate on the physiological effects of caffeine in plants (i.e. photosynthetic parameters). Moreover, the findings of this study suggest that high doses of caffeine could be used as a natural herbicide for plants such as tobacco due to its lethal effect on plant growth.

\section{References}

Alkhatib R., Alkhatib B., AL-Quraan N. et al.: Impact of exogenous caffeine on morphological, biochemical, and ultrastructural characteristics in Nicotiana tabacum var. Turkish. - Biol. Plantarum 60: 706-714, 2016.

Alkhatib R., Bsoul E., Blom D.A. et al:: Microscopic analysis of lead accumulation in tobacco (Nicotiana tabacum var. Turkish) roots and leaves. - J. Microsc. Ultrastruct. 1: 57-62, 2013.

Anaya A., Waller G.R., Okinda-Owuor P. et al.: The Role of Caffeine in the production decline due to autotoxicity in coffee and tea plantations. - In: Reigosa M., Pedrol N. (ed.): Allelopathy: from Molecules to Ecosystems. Pp. 71-91. Science Publishers Inc., Enfield 2002.

Ashihara H., Crozier A.: Biosynthesis and catabolism of caffeine in low-caffeine-containing species of Coffea. - J. Agric. Food Chem. 47: 3425-3431, 1999.

Ashihara H., Crozier A.: Caffeine: a well known but little mentioned compound in plant science. - Trends Plant Sci. 6: 407-413, 2001.

Ashihara H., Sano H., Crozier A.: Caffeine and related purine alkaloids: biosynthesis, catabolism, function and genetic engineering. - Phytochemistry 69: 841-856, 2008

Čiamporová M.: The development of structural changes in epidermal ceils of maize roots during water stress. - Biol. Plantarum 29: 290-294, 1987.

Čiamporová M., Mistrík I.: The Impact of the environment on roots and root systems the ultrastructural response of root cells to stressful conditions. - Environ. Exp. Bot. 33: 11-26, 1993.

Coetzee J., van der Merwe C.F.: Some characteristics of the buffer vehicle in glutaraldehyde-based fixatives. - J. Microsc. 146: $143-155,1987$.

Curlango-Rivera G., Duclos V.D., Ebolo J.J., Hawes C.M.: Transient exposure of root tips to primary and secondary metabolites: Impact on root growth and production of border cells. - Plant Soil 332: 267-275, 2010

Dhanapackiam S., Iiyas M.H.: Effect of salinity on chlorophyll and carbohydrate contents of Sesbania grandiflora seedlings. Indian J. Sci. Technol. 3: 64-66, 2010.

Epstein M.A., Holt S.J.: The localization by electron microscopy of hela cell surface enzymes splitting adenosine triphosphate. J. Cell. Biol. 19: 325-336, 1963. 
Ferreira J.S., Duke S.O., Vaughn K.C.: Histochemical and immunocytochemical localization of tropane alkaloids in Erythroxylum coca var. coca and E. novogranatense var. novogranatense. - Int. J. Plant Sci. 159: 492-503, 1998.

Gilbert G.A., Wilson C., Madore M.A.: Root-zone salinity alters raffinose oligosaccharide metabolism and transport in coleus. - Plant Physiol. 115: 1267-1276, 1997.

Hadacek F., Kraus G.F.: Plant root carbohydrates affect growth behaviour of endophytic microfungi. - FEMS Microbiol. Ecol. 41: 161-170, 2002.

Hajibagheri M.A., Yeo A.R., Flowers T.J.: Salt tolerance in Suaeda maritima (L.) Dum. Fine structure and ion concentrations in the apical regions of roots. - New Phytol. 99: 331343, 1985.

Hajibagheri M.A., Harvey D.M., Flowers T.J.: Quantitative ion distribution withir/root cells of salt-sensitive and salt-tolerant maize varieties. - New Phytol. 105: 367-379, 1987.

Hollingsworth R.G., Armstrong J.W., Campbell E.: Caffeine as a repellent for slugs and snails. - Nature 417: 915-916, 2002.

Khanam N., Khoo C., Close R., Khan A.G.: Organogenesis, differentiation and histolocalization of alkaloids in cultured tissues and organs of Duboisia myoporoides R. Br. - Ann. Bot.London 86: 745-752, 2000.

Kim Y.S., Uefuji H., Ogita S., Sano H.: Transgenic tobacco plants producing caffeine: a potential new strategy for insect pest control. - Transgenic Res. 15: 667-672, 2006.

Krapp A., Stitt M.: An evaluation of direct and indirect mechanisms for the "sink-regulation" of photosynthesis in spinach: changes in gas exchange, carbohydrates, metabolites, enzyme activities and steady state transcript levels after coldgirdling source leaves. - Planta 195: 313-323, 1995.

Kumar G., Tripathi A.: Mutagenic response of caffeine in Capsicum annuum. - J. Indian Bot. Soc. 83: 136-140, 2004.

Mathavan S., Premalatha Y., Christopher M.M.: Effects of caffeine and theophylline on the fecundity of four lepidopteran species. - Exp. Biol. 44: 133-138, 1985.

Mohanpuria P., Yadav S.K.: Retardation in seedling growth and induction of early senescence in plants upon caffeine exposure is related to its negative effect on Rubisco. Photosynthetica 47: 293-297, 2009.

Mondolot L.P., Fisca L.A., Buatois B. et al.: Evolution in caffeoylquinic acid content and histolocalization during Coffea canephora leaf development. - Ann. Bot.-London 98: 33-40, 2006.

Montes O., Diánez F., Camacho F.: Doses of caffeine on the development and performance of pepper crops under greenhouse. - Hortic. Bras. 32: 398-403, 2014.

Nishizawa N.K., Tainaka H., Okubo A. et al:: Desiccationinduced heterophagy in plant root cells. - In: Krebs K.H., Richter H., Hinckley T.M (ed.): Structural and Functional Responses to Environmental Stresses: Water Shortage. Pp. 99111. SPB Acad. Publ., The Hague 1989.

Pietrini F., Iannelli M.A., Pasqualini S., Massacci A.: Interaction of cadmium with glutathione and photosynthesis in developing leaves and chloroplasts of Phragmites australis (Cav.) Trin. ex Steudel. - Plant Physiol. 133: 829-837, 2003.

Reynolds E.S.: The use of lead citrate at high $\mathrm{pH}$ as an electronopaque stain in electron microscopy. - J. Cell Biol. 17: 208212, 1963.

Spurr A.R.: A low-viscosity epoxy resin embedding medium for electron microscopy. - J. Ultrastruct Res. 26: 31-43, 1969.

Sun A.Z., Guo F.Q.: Chloroplast retrograde regulation of heat stress responses in plants. - Front. Plant Sci. 7: 398, 2016.

Vartapetian B.B., Andreeva I.N., Generozova I.P. et al: Functional electron microscopy in studies of plant response and adaptation to anaerobic stress. - Ann. Bot.-London 91: 155172, 2003.

Vinocur B., Altman A.: Recent advances in engineering plant tolerance to abiotic stress: achievements and limitations. Curr. Opin. Biotechnol. 16: 123-132, 2005. 